\title{
Is Inflammatory Bowel Disease More Severe when It Appears at Younger Ages?
}

\author{
Gerhard Rogler \\ Departement für Innere Medizin, Klinik für Gastroenterologie und Hepatologie, Universitätsspital Zürich, \\ Zürich, Schweiz
}

In this issue of Digestion, Lee and coworkers try to answer the important question whether patients with ulcerative colitis (UC) diagnosed at a young age have more severe disease activity than patients diagnosed when older [1]. Similar to the situation in older inflammatory bowel disease patients, disease behavior varies dramatically among children, adolescents and younger patients. Therefore, conflicting data have been published. However, recent evidence suggests that at least in the case of pediatric onset of UC the disease may present differently and show a different behavior as compared to onset of disease at older ages.

UC usually is diagnosed in late adolescence and early adulthood. However, also older patients are not rare as the number of total cases increased in recent years. Epidemiological studies have shown that in $40-50 \%$ of adult patients with UC, inflammation is restricted to the rectum or sigmoid colon. In contrast, $25-35 \%$ of patients have extended disease or pancolitis $[2,3]$. With respect to this, pediatric UC has been shown to behave clearly different. Approximately $60-70 \%$ of patients with pediatric onset of UC present with pancolitis, as opposed to approximately $20-30 \%$ in adults $[4,5]$. In pediatric patients, proctitis is a very unusual manifestation of the disease.

Data on the natural history of UC in different age groups are scarce. The interpretation of the natural his- tory is complicated by the fact that treatment options have changed dramatically during the last 10 years. Therefore, most of the historic cohort data are only of limited value today. A more recent study from a larger North American registry demonstrated that at onset of UC, about $80 \%$ of pediatric patients had pancolitis, $80 \%$ had moderate to severe colitis, and $80 \%$ received corticosteroids within 30 days of diagnosis. A steroid-dependent disease course was found in $45 \%$ at 1 year, which is clearly higher compared with adult patients [5]. The increased severity of disease in this population is further illustrated by the fact that $5 \%$ of those patients had to undergo colectomy within a year of diagnosis. Levine [6] subsequently concluded that pediatric UC not only presents with more extensive disease, but also with more severe and refractory disease. It is obvious that this has a negative influence on the quality of life [7].

The data of Lee et al. [1] further support a more severe disease course of UC at younger ages. They performed a retrospective study on 455 patients with UC who were diagnosed and treated between 1990 and 2008 at a single tertiary institution in Korea. They divided the patients into two groups: one older and one younger than 40 years at diagnosis. Disease severity, frequency of pancolitis, and steroid use rate were found to be higher in the young patients. In contrast to the findings of the pediatric co-

\section{KARGER}

Fax +41613061234 E-Mail karger@karger.ch www.karger.com
(C) 2010 S. Karger AG, Base

$0012-2823 / 10 / 0814-0235 \$ 26.00 / 0$

Accessible online at:

www.karger.com/dig
Gerhard Rogler

Universitätsspital Zürich, Klinik für Gastroenterologie und Hepatologie,

Departement für Innere Medizin

Rämistrasse 100, CH-8091 Zürich (Switzerland)

Tel. +41 44255 9477, Fax +41 44255 9497, E-Mail gerhard.rogler@ usz.ch 
hort, surgery rates were not significantly different between the two groups. This indicates one of the limitations of the study: Similar to what has been discussed in Crohn's disease with respect to the Vienna classification (and now has resulted in the Montréal classification), the discrimination between patients older or younger than 40 years is too crude [8]. In the Montreal classification for Crohn's disease, the age group younger than 40 years was split into two groups: A1 below 16 years and A2 between 17 and 40 years. The third group is the age group above 40 years [8]. It is important to use similar age groups in future analyses to learn more about age-related disease behavior of UC. This can help understand the specific needs of each age group and improve age-specific treatment.

\section{References}

1 Lee JH, Cheon JH, Moon CM, Park JJ, Hong SP, Kim TI, Kim WH: Do patients with ulcerative colitis diagnosed at a young age have more severe disease activity than patients diagnosed when older? Digestion 2010;81:237243.

2 Henriksen M, Jahnsen J, Lygren I, Sauar J, Kjellevold O, Schulz T, et al: Ulcerative colitis and clinical course: results of a 5-year population-based follow-up study (the IBSEN study). Inflamm Bowel Dis 2006;12: 543-550.
- 3 Henriksen M, Jahnsen J, Lygren I, Sauar J, Schulz T, Stray N, et al: Change of diagnosis during the first five years after onset of inflammatory bowel disease: results of a prospective follow-up study (the IBSEN Study). Scand J Gastroenterol 2006;41:1037-1043.

-4 Heyman MB, Kirschner BS, Gold BD, Ferry G, Baldassano R, Cohen SA, et al: Children with early-onset inflammatory bowel disease (IBD): analysis of a pediatric IBD consortium registry. J Pediatr 2005; 146:35-40.

5 Hyams J, Markowitz J, Lerer T, Griffiths A, Mack D, Bousvaros A, et al: The natural history of corticosteroid therapy for ulcerative colitis in children. Clin Gastroenterol Hepatol 2006;4:1118-1123.
6 Levine A: Pediatric inflammatory bowel disease: is it different? Dig Dis 2009;27:212214.

7 Greth J, Torok HP, Koenig A, Folwaczny C: Comparison of inflammatory bowel disease at younger and older age. Eur J Med Res 2004;9:552-554.

8 Satsangi J, Silverberg MS, Vermeire S, Colombel JF: The Montreal classification of inflammatory bowel disease: controversies, consensus, and implications. Gut 2006;55: 749-753. 